\title{
Characteristics of Stress Transfer and Progressive Fracture in Overlying Strata due to Mining-Induced Disturbances
}

\author{
Xiang-feng Lv (D), ${ }^{1}$ Hong-yuan Zhou, ${ }^{1}$ Ai-wen Wang, ${ }^{2}$ Chun Feng, ${ }^{3}$ and Xiao-chun Xiao ${ }^{2}$ \\ ${ }^{1}$ Geotechnical Engineering Research Center, Institute of Municipal Engineering, Beijing 100037, China \\ ${ }^{2}$ School of Mechanics and Engineering, Institute of Rock Burst, Liaoning Technical University, Fuxin, Liaoning 123000, China \\ ${ }^{3}$ Key Laboratory for Mechanics in Fluid Solid Coupling Systems, Institute of Mechanics, Chinese Academy of Sciences, \\ Beijing, China \\ Correspondence should be addressed to Xiang-feng Lv; szgcyjylvxiangfeng@163.com
}

Received 6 March 2018; Accepted 10 July 2018; Published 9 August 2018

Academic Editor: Gaofeng Zhao

Copyright ( 2018 Xiang-feng Lv et al. This is an open access article distributed under the Creative Commons Attribution License, which permits unrestricted use, distribution, and reproduction in any medium, provided the original work is properly cited.

\begin{abstract}
In this study, based on the mining of the 13210 working face in the Yima coal mine of the Gengcun village, China, a simplified mechanical model for the analysis of dynamic destabilization of the overlying strata during underground mining was constructed. The numerical simulation was used to analyze the stress patterns in the advanced abutments of the tunnel face and the characteristics of dynamic failures in the overlying strata. Furthermore, similitude experiments were conducted to study the process of stress release and deformation in the overlying strata, and to analyze the effects of overburden destabilization on the ground surface settlement. The theoretical analysis indicated that if the geometric parameters of a working face are fully determined, a stiffness ratio no greater than 1 is required for dynamic destabilization to occur. The numerical simulation results show that the stress in the overlying strata decreases with a decrease in distance from the tunnel face. The stresses in the advanced abutments initially increase with an increase in distance from the tunnel face, followed by a decrease in stress, and an eventual stabilization of the stress levels; this corresponds to the existence of a "stress build-up zone," "stress reduction zone," and "native rock stress zone." In similitude experiments, it was observed that a "pseudoplastic beam" state arises after the local stresses of the overlying strata have been completely released, and the "trapezoidal" fractures begin to form at stress concentrations. If the excavation of the working face continues to progress, the area of collapse expands upward, thereby increasing the areas of the fracture and densification zones. Owing to the nonuniform settlement of the overlying strata and the continuous development of bed-separating cracks, secondary fractures will be generated on both sides of the working face, which increase the severity of the ground surface settlement.
\end{abstract}

\section{Introduction}

In recent years, problems caused by underground mining, such as surface subsidence, rock burst failures in the working face, and overlying strata fractures, have become increasingly prominent [1]. Since the inception of mining subsidence studies in the beginning of the twentieth century, a large body of research works has accumulated on mininginduced ground settlement and overlying strata failures. These research works generally include theoretical analyses, numerical calculations, and experimental studies. The theoretical studies on mining subsidence helped develop the masonry beam theory [2], key strata theory [3, 4], and supporting plate theory [5]. The numerical approaches may be generally divided into two categories. The first category pertains to methods based on continuum mechanics, for example, the finite element method (FEM), finite difference method (FDM), boundary element method (BEM), and element-free method (EFM). The second category of methods is based on discontinuum mechanics, which includes the discrete element method (DEM) and discontinuous deformation analysis (DDA) [6-8]. In experimental studies, the similitude experiment is the most broadly used experimental tool for studying 
ground subsidence. These experiments are straightforward to perform and provide an accurate reflection upon mining-induced ground deformations and change patterns in overburden stresses.

In this study, we briefly discuss the most important gaps in the current literature regarding stress transfers and failures in the overlying strata during underground mining processes. In the theoretical aspect, the mechanisms of rock burst failures in the overburden during underground mining remain unclear, and a consistent understanding is yet to be achieved on the overburden's deformation and failure processes, or its stress distribution patterns. In numerical simulations, the FEM and FDM are highly effective methods for simulating the properties of a material in continuum states. However, these methods are incapable of simulating the process in which a material changes from a continuous to discontinuous state, and they cannot reveal the dynamics of a material in a discontinuous state. The block-discrete element method (B-DEM) and granular DEM have certain advantages in the simulation of noncontinuum dynamics; however, it is still difficult to simulate the continuous deformation processes of a material using these methods [9]. Although similitude experiments can produce patterns that are consistent with actual engineering works, these experiments lack in precision. Consequently, the similitude experiment results often have to be verified against theoretical analyses or numerical calculations.

In this study, we constructed a mechanical model for the analysis of dynamic failures in a working face, in the presence of disturbances caused by underground mining, based on the effects of working face excavation on the stress states of the overlying strata. Further, this model was used to provide the criterion for the dynamic failures in the overburden of the working face. Based on the numerical methods of the continuum-discontinuum element method (CDEM), FEM and DEM were coupled to each other to simulate the deformations and dynamics of the overburden in continuous and discontinuous states. This allows the progressive failure of the overlying strata to be analyzed as it transitions from a continuous mass to a discontinuous mass. The similitude experiments were conducted to investigate the stress relief and deformation in the overburden and to analyze the effects of overburden failure on the ground settlement. Finally, the dynamics of stress transfers and failures in the overburden during mining process were obtained via a comprehensive analysis of the results obtained from our theoretical analyses, numerical calculations, and similitude experiments.

\section{A Dynamic Model for Underground Resource Mining}

During the underground mining processes, the stress state of the overburden changes from the native state to a state with rising axial stresses and decreasing confining stresses, until failure finally occurs. The overburden failure and destabilization is triggered by the superposition of dynamic and static loading; this is already broadly recognized and accepted as a dynamic problem [10-12]. In [13-15], it was observed that the excavation-induced unloading transforms the triaxial stress state of the overburden around the working face into a biaxial stress state, causing a rapid release in the stresses that were concentrated within the overburden, thereby triggering dynamic failures. Based on this analysis, we devised a simplified mechanical model for the analysis of dynamic overburden failures during the excavation of a working face using the 13210 working face in the Yima coal mine of the Gengcun village as an example, as shown in Figure 1.

Supposing that $p_{\mathrm{db}}$ is the pressure acting on the roof, $k_{\mathrm{db}}$ is the stiffness of the roof, $u_{\mathrm{db}}$ is the deformation of the roof, $p_{s}$ is the load acting on the elastoplastic zone, $k_{s}$ is the stiffness of the elastoplastic zone, $p_{t}$ is the load acting on the elastic zone, $k_{t}$ is the stiffness of the elastic zone, $a$ is the total sinkage of the roof, $u_{c}$ is the deformation of the excavation layer, and the roof may be treated as an elastic body. The conditions for equilibrium are as follows:

$$
\begin{aligned}
& p_{\mathrm{db}}=p_{s}+p_{t}, \\
& p_{\mathrm{db}}=k_{\mathrm{db}} u_{\mathrm{db}}, \\
& u_{\mathrm{db}}=a-u_{c} .
\end{aligned}
$$

In [16], it was observed that strain softening occurs in the elastoplastic zone of rock masses. Therefore, a nonlinear constitutive equation is used here:

$$
\sigma=E \varepsilon e^{-\left(\varepsilon / \varepsilon_{c}\right)},
$$

where $E$ is the initial elastic modulus and $\varepsilon_{c}$ is the peak strain.

The elastoplastic zone of the excavation strata has a width of $B$ and a thickness of $H$. The relationship between load and deformation under unit length conditions is as follows:

$$
p_{s}=\sigma S=\frac{E B}{H} u_{c} e^{-\left(u_{c} / u_{0}\right)}=\lambda u_{c} e^{-\left(u_{c} / \mathrm{u}_{0}\right)},
$$

where $\lambda=E B / H$ is the initial stiffness and $u_{0}$ is the settlement of the roof when the roof's strain reached the peak value. The second derivative of (3) was taken to determine the inflection point of the load-versus-deformation curve for the elastoplastic zone; an inflection point occurs at $u_{c}=u_{1}=2 u_{0}$, and the absolute gradient of the curve is $\lambda_{1}=\lambda e^{-2}$. Refer to [13] to determine the energy composition of the overlying strata. The system strain energy consists of the top plate and excavation layer strain energies. The total potential energy is as follows:

$$
V(u)=\int_{0}^{u_{c}} \lambda u_{c} e^{u_{c} / u_{0}} d u_{c}+\frac{1}{2} k_{\mathrm{db}}\left(a-u_{c}\right)^{2}+\frac{1}{2} k_{t} u_{c}^{2}
$$

The first derivative of (4) was set to 0 to obtain the equilibrium surface equation:

$$
V^{\prime}(u)=\lambda u_{c} e^{u_{c} / u_{0}}+k_{\mathrm{db}}\left(a-u_{c}\right)+k_{t} u_{c}=0 .
$$

The deformation at the cusp of the equilibrium surface, $u_{c}=u_{1}=2 u_{0}$, is exactly the same as the inflection point of the elastoplastic zone's constitutive curve. The Taylor expansion was performed on (5) with $u=u_{1}$ up to the third term, which gives 

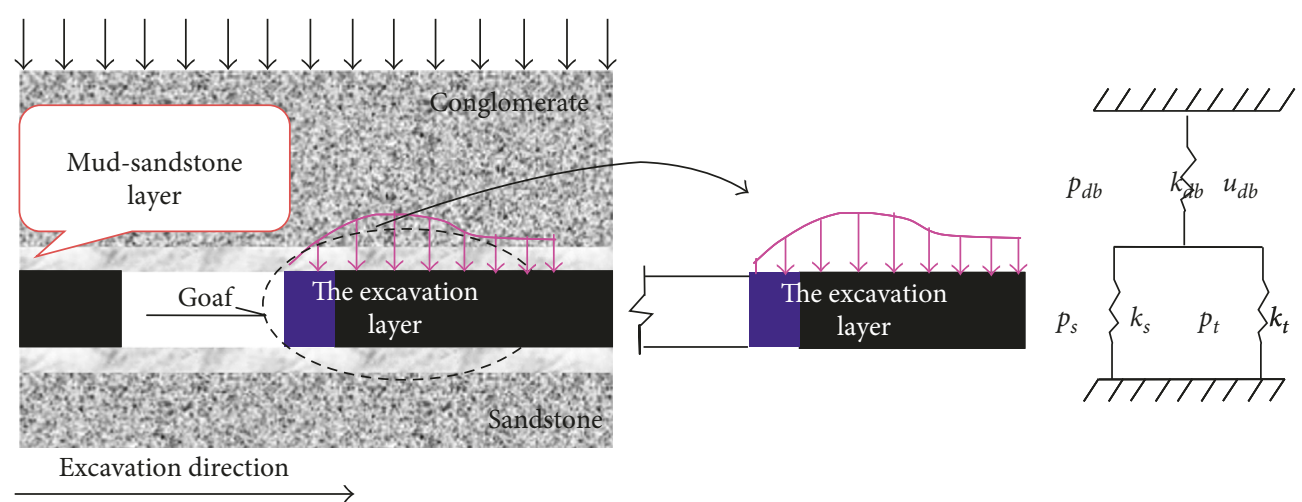

FIgURE 1: Simplified mechanical model for the analysis of underground mining.

$$
\begin{aligned}
\frac{3}{2}[1 & \left.-\frac{k_{d}}{\lambda e^{-2}} \frac{\left(a-u_{1}\right)}{u_{1}} \frac{k_{t}}{\lambda e^{-2}}\right] \\
& +\frac{3}{2}\left[\frac{\left(k_{\mathrm{db}}+k_{t}\right)}{\lambda e^{-2}}-1\right]\left(\frac{u-u_{1}}{u_{1}}\right)+\left(\frac{u-u_{1}}{u_{1}}\right)^{3}=0 .
\end{aligned}
$$

The point mutation theory discussed in [17] was used to obtain the standard form of the surface equation:

$$
x^{3}+p x+q=0
$$

where $x=\left(u-u_{1}\right) / u_{1}$ is the state variable of the system, while $p$ and $q$ are the control variables:

$$
\begin{aligned}
& p=\frac{3}{2}\left[\frac{\left(k_{\mathrm{db}}+k_{t}\right)}{\lambda e^{-2}}-1\right]=\frac{3}{2}(k-1), \\
& q=\frac{3}{2}\left[1-\frac{k_{\mathrm{db}}}{\lambda e^{-2}} \eta+\frac{k_{t}}{\lambda e^{-2}}\right] \\
& k=\frac{k_{\mathrm{db}}+k_{t}}{\lambda e^{-2}} \\
& \eta=\frac{a-u_{1}}{u_{1}}
\end{aligned}
$$

where $\eta$ is a dimensionless parameter that is a function of $a$. The bifurcation set is as follows:

$$
4 p^{3}+27 q^{2}=0
$$

The substitution of (8), (9), (10), and (11) into (12) yields the following:

$$
2(k-1)^{3}+9\left[1-\frac{k_{\mathrm{db}}}{\lambda e^{-2}} \eta+\frac{k_{t}}{\lambda e^{-2}}\right]^{2}=0 .
$$

Equation (13) is the mechanical criterion for the occurrence of rock burst failures in this system. Based on (13), it can be inferred that a sudden change occurs in the system when $p \leq 0$; which implies that $k \leq 1$ is a prerequisite for the occurrence of sudden destabilizations in the system. Therefore, one of the conditions for the occurrence of dynamic failures in the overlying strata of this study is a stiffness ratio no greater than 1 . Furthermore, a dynamic failure can occur only if soft softening has occurred in the overburden after the geometric parameters were fully determined.

\section{Continuous-Discontinuous Deformation Theory of Overlying Strata during Underground Mining}

3.1. Basic Principle. According to the dynamic model for underground resource mining, the continuum-based discrete element theory is adopted is this study [18]. It contains two kinds of elements: blocks and contacts [19] (Figure 2). A discrete block consists of one or more FEM elements that share the same nodes and faces. A contact contains several normal and tangent springs, and each spring owns two nodes that belong to two different blocks. The FEM is used inside a block; while the DEM is adopted for a contact.

3.2. Governing Equation. In the discontinuous deformation theory, the governing equation is the motion equation. The block is subjected to internal and external forces. The internal force includes the damping and deformation forces. The external force includes the external boundary force and the force between springs. As the block body is regarded as a continuous and isotropic linear elastic body, its mechanical properties can be described by the basic differential equations of three-dimensional elastodynamics [20,21], which are as follows:

equilibrium equation:

$$
\sigma_{i j, j}+f_{i}-\rho u_{i, n}-\mu u_{i}=0
$$

geometric equation:

$$
\varepsilon_{i j}=\frac{1}{2}\left(u_{i, j}+u_{j, i}\right)
$$

physical equation:

$$
\sigma_{i j}=\lambda \delta_{i j} \varepsilon_{k k}+2 G \varepsilon_{i j}
$$

Boundary condition: $u_{i}=\bar{u}_{i}$ (on the displacement boundary of $\Gamma_{u}$ ) and $\sigma_{i j} n_{j}=T_{i}$ (on the force boundary of $\Gamma_{\sigma}$ ). 
Here, $\sigma_{i j}, u_{i}, f_{i}$, and $T_{i}$ are the stress, displacement, volume force, and area force, respectively; $\Omega$ and $\Gamma$ denote the rock block region and its boundary, respectively; $\Gamma=\Gamma_{u} \cup \Gamma_{\sigma}, \lambda$ and $G$ are the Lame constants; $\rho$ and $\mu$ denote the mass density and damping coefficient, respectively; and $\delta_{i j}$ is the Kronecker delta function.

Based on the elastic variational principle [20], the governing equation is as follows:

$$
[M]\{\ddot{u}(t)\}+[C]\{\dot{u}(t)\}+[K]\{u(t)\}=\{Q(t)\},
$$

where $\ddot{u}(t), \dot{u}(t)$, and $u(t)$ are the acceleration, speed, and displacement arrays, respectively. $[M],[C],[K]$, and $[Q]$ are the mass matrix, damping matrix, stiffness matrix, and nodal load array, respectively.

When we solve the governing equations, the first step is to loop each deformable block and calculate the corresponding continuous deformation. The second step is to calculate the surface force. When we calculate the surface force, the stiffness matrix and nodal displacement are used to calculate the elastic force; the damping matrix and nodal velocity are used to calculate the damping force. Finally, the equation of motion is solved using the direct integral method. The specific equations are as follows:

elastic force:

$$
\left[\begin{array}{cccc}
K_{1,1} & K_{1,2} & \cdots & K_{1, n} \\
K_{2,1} & K_{2,2} & \cdots & K_{2, n} \\
\vdots & \vdots & \vdots & \vdots \\
K_{n, 1} & K_{n, 2} & \cdots & K_{n, n}
\end{array}\right]\left[\begin{array}{c}
u_{1} \\
u_{2} \\
\vdots \\
u_{n}
\end{array}\right]=\left[\begin{array}{c}
f_{1} \\
f_{2} \\
\vdots \\
f_{n}
\end{array}\right] .
$$

damping force:

$$
\left[\begin{array}{cccc}
C_{1,1} & C_{1,2} & \cdots & C_{1, n} \\
C_{2,1} & C_{2,2} & \cdots & C_{2, n} \\
\vdots & \vdots & \vdots & \vdots \\
C_{n, 1} & C_{n, 2} & \cdots & C_{n, n}
\end{array}\right]\left[\begin{array}{c}
v_{1} \\
v_{2} \\
\vdots \\
v_{n}
\end{array}\right]=\left[\begin{array}{c}
f_{1}^{\prime} \\
f_{2}^{\prime} \\
\vdots \\
f_{n}^{\prime}
\end{array}\right] .
$$

Solution of the equation of motion using the direct integral method:

$$
\begin{aligned}
& a_{i}=\frac{f_{i}+f_{i}^{\prime}+f_{i}^{\text {out }}}{m_{i}}, \\
& v_{i}=v_{i}^{t-1}+a_{i} t, \\
& u_{i}=u_{i}^{t-1}+v_{i} t .
\end{aligned}
$$

The acceleration, velocity, and displacement of the block body nodes can be calculated by (20), where $f_{i}^{\text {out includes }}$ the interface and contact forces. It is observed that the interface force is determined by the boundary conditions.

3.3. Model Boundary. Based on the block contact theory proposed in [19], a mechanical model is proposed to describe the interaction between the two blocks. When the deformation of the material is continuous, the force between adjacent blocks is calculated based on the nodal displacement:

$$
\begin{gathered}
F_{\mathrm{n}}=-K_{\mathrm{n}} \Delta u_{\mathrm{n}}, \\
F_{\mathrm{s}}=-K_{\mathrm{s}} \Delta u_{\mathrm{s}},
\end{gathered}
$$

where $F_{\mathrm{n}}$ is the normal force of the spring, $K_{\mathrm{n}}$ is the normal stiffness of the spring, $\Delta u_{\mathrm{n}}$ is the normal displacement vector difference for the spring-connected blocks, $F_{s}$ is the tangential force of the spring, $K_{\mathrm{s}}$ is the tangential stiffness of the spring, and $\Delta u_{\mathrm{s}}$ is the tangential displacement vector difference for the spring-connected blocks.

When the deformation of the material is discontinuous, the fracture of the spring is used to simulate deformation. The spring has two types of damage: tensile and shear failures. When the normal force of the spring is greater than the tensile strength of the material, the material suffers from tensile failure. The normal and tangential forces between the adjacent blocks are zero, that is,

$$
\begin{aligned}
& F_{\mathrm{n}}=0, \\
& F_{\mathrm{s}}=0 .
\end{aligned}
$$

After the spring suffers from the shear failure, the blocks will slide relative to each other; thus, there is pressure and friction. Among them, the pressure is equal to the product of the normal stiffness of the spring and the difference of the displacement vector, and the friction is equal to the product of the normal force and the friction coefficient. Under these conditions, the direction of friction is opposite to the motion direction of the block. Thus,

$$
\begin{aligned}
& F_{\mathrm{n}}=-K_{\mathrm{n}} \Delta u_{\mathrm{n}}, \\
& F_{\mathrm{s}}=F_{\mathrm{n}} \times \tan \varphi,
\end{aligned}
$$

where $\tan \varphi$ is the friction coefficient and $\varphi$ is the internal friction angle of the material.

3.4. Calculation Steps. The dynamic relaxation method discussed in [22] is used to solve equations. The static problem is transformed into a dynamic problem by introducing damping. Figure 3 shows the main process of this method.

\section{Numerical Simulation and Physical Model Test for Underground Mining}

4.1. Calculation Method and Model Parameters. The CDEM was used to perform the numerical calculations in this study. The numerical model shown in Figure 4 is established according to the actual size of the 13210 working face at the YIMA Gengcun (China) coal mine. The model size is set as $300 \times 150 \times 83 \mathrm{~m}$. The model is divided into four layers, from top to bottom, as conglomerate, roof, coal, and floor; and their thicknesses are $44 \mathrm{~m}, 15 \mathrm{~m}, 9 \mathrm{~m}$, and $15 \mathrm{~m}$, respectively. The horizontal and vertical stresses are 20 and $17 \mathrm{MPa}$, respectively, and the depth of each mining is $4 \mathrm{~m}$. The rectangular roadway section has a length of $5 \mathrm{~m}$ and a width of $4 \mathrm{~m}$. The bottom surface of the model is fully constrained, the horizontal level of the model is surrounded, and the roof is a free surface. The working face is shown in Figure 4, and the numerical calculation model is 


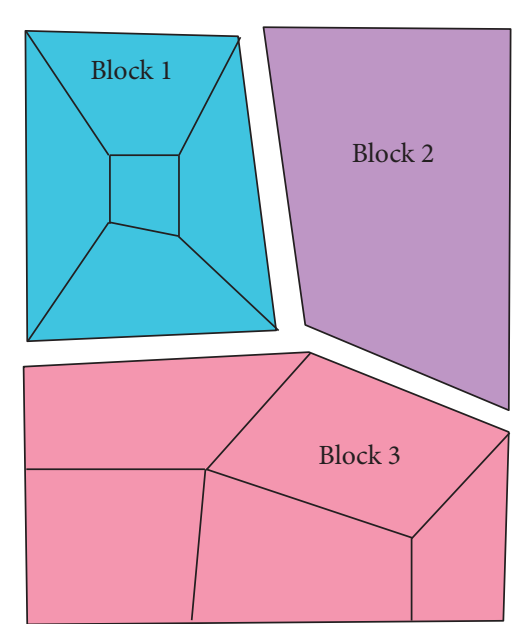

Block 1: 5 FEM elements Block 2: 1 FEM element Block 3: 5 FEM elements

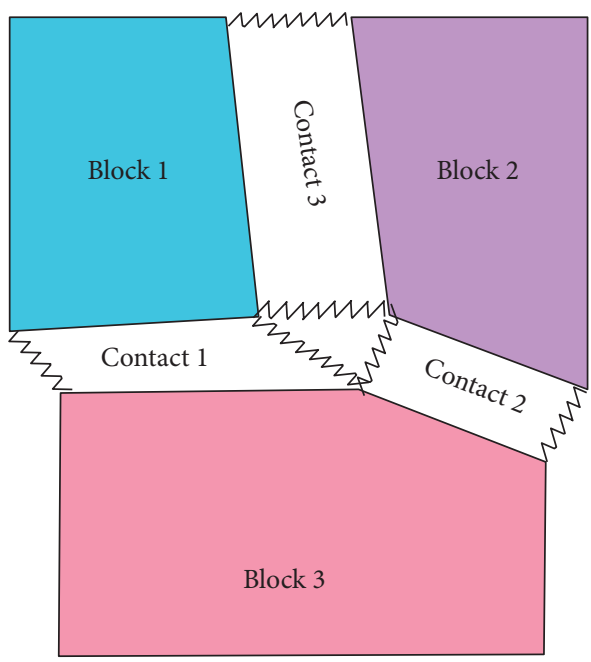

Contact 1: 4 normal and 4 tangent springs Contact 2: 4 normal and 4 tangent springs Contact 3: 4 normal and 4 tangent springs

Figure 2: Blocks and interfaces for 8 nodes hexahedron [19].

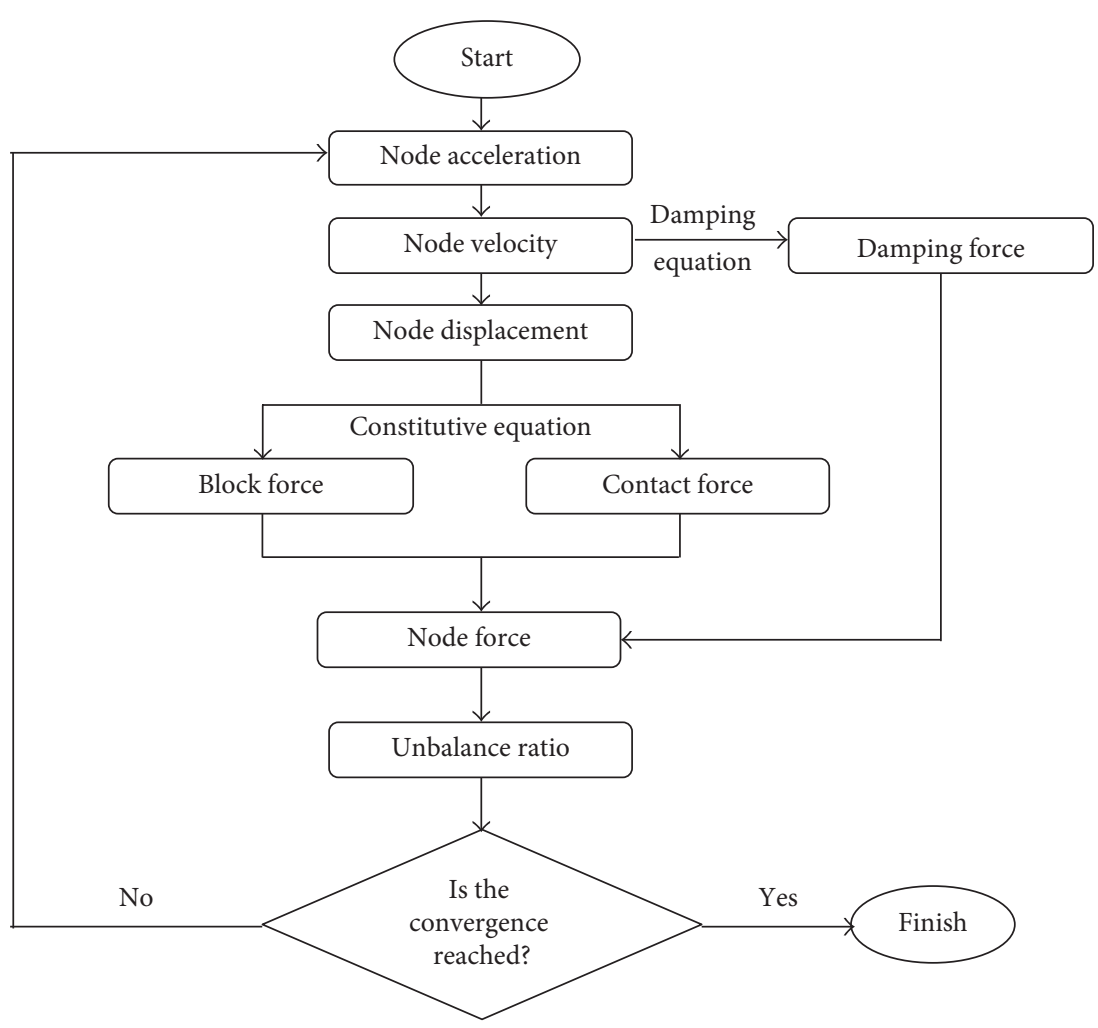

FIGURE 3: Main process to solve a problem.

shown in Figure 5. Referring to the arrangement of the stress and displacement monitors (\#1, \#2, \#3, and \#4) shown in Figure 5, the monitor points for the numerical simulation were set. In Figure 5, the different colors represent the geologic bodies with different mechanical properties. Groups 1-4 represent the conglomerate, roof, coal, and floor, respectively. Groups 5-17 represent the raw coal with different mechanical properties in front of the working face. The basic mechanical parameters of groups 1-17 are shown in Table 1.

4.2. Stress Transfer Law and Distribution Characteristics of Overlying Strata during the Working Face Mining. The 


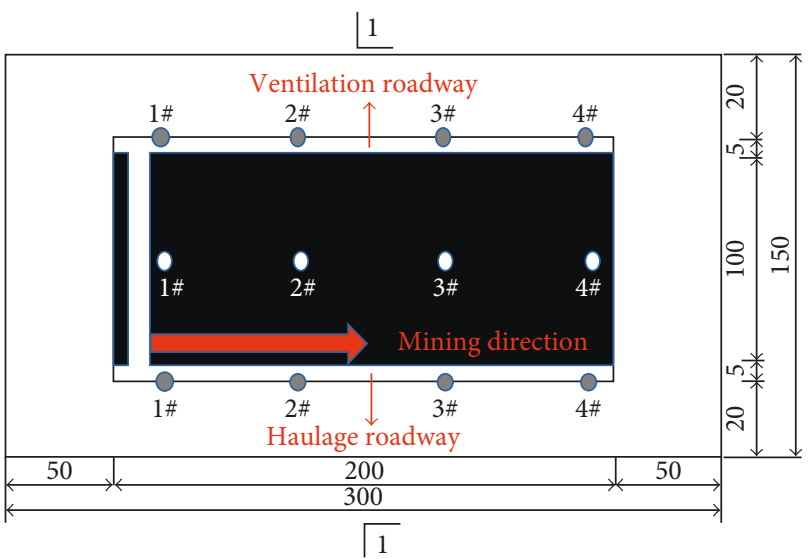

(a)

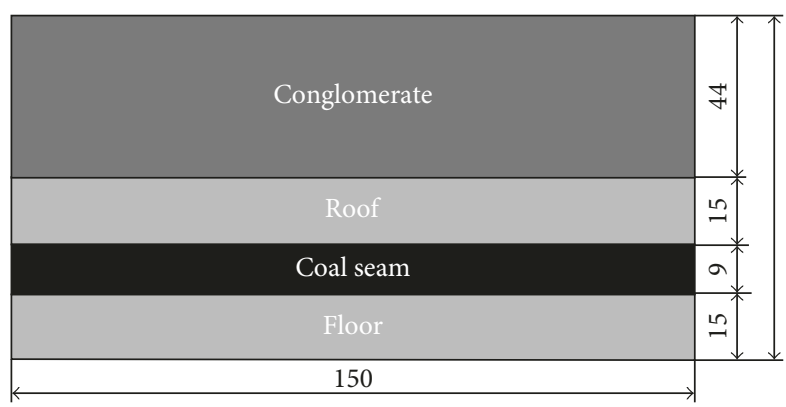

(b)

FIgURE 4: (a) Actual working face layout and measuring points arrangement (unit: m); (b) profile 1 (unit: m).

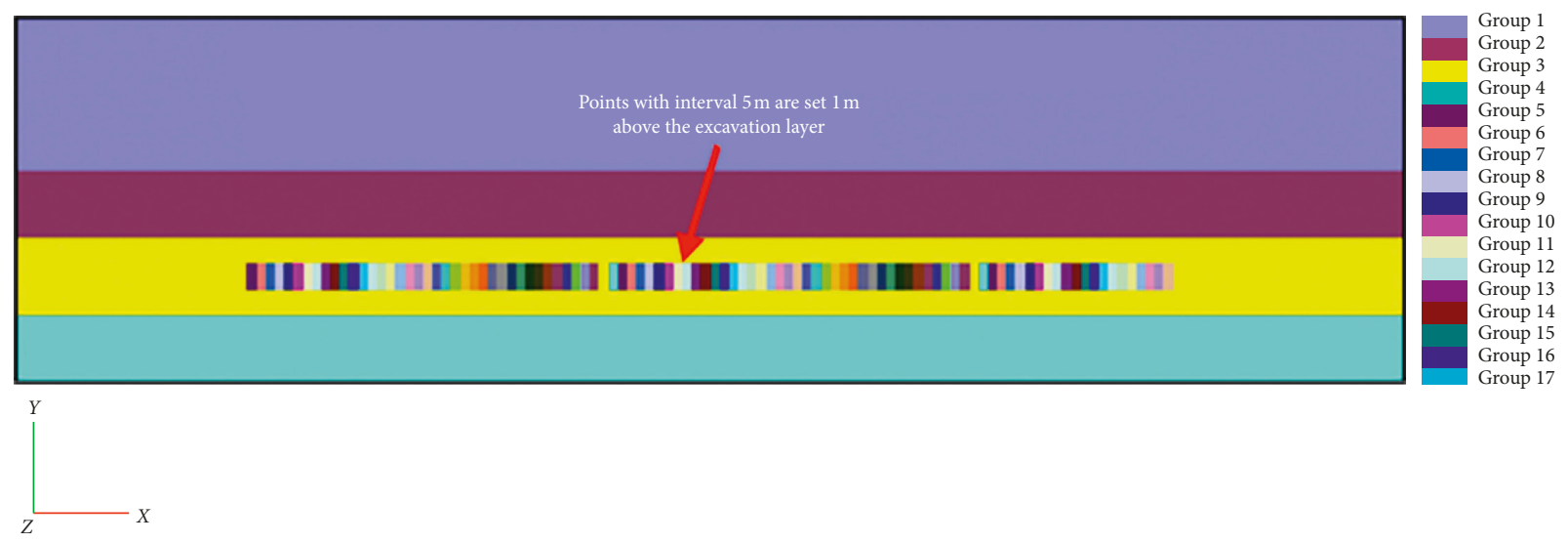

FIgURE 5: The numerical calculation model.

stresses of the advanced abutments and the deformational patterns of the overlying strata during mining conditions are shown in Figure 6. Figure 6(a) shows that the deformation of the overburden is relatively small during the initial stages of working face mining (advancement up to $4 \mathrm{~m}$ ), and the deformation of the overburden increases with a decrease in distance from the tunnel face. The deformation of the overburden decreases and eventually stabilizes with an increase in distance from the tunnel face. In addition, it is observed that the stress values decrease with a decrease in distance from the tunnel face. As this distance increases, the advanced abutments of the tunnel face exhibit an increase in stress, followed by a decrease, and finally the stabilization of stress levels; this is indicative of the existence of a "stress build-up zone," "stress reduction zone," and "native rock stress zone." The stress monitoring data also indicate that the area of effect of the working face's excavation is approximately $30 \mathrm{~m}$, and the stress peak is located approximately $16 \mathrm{~m}$ in front of the tunnel face.

The continued excavation of the working face expands the area of the goaf and increases the deformation of the overlying strata. The stresses of the abutments gradually propagate toward the front of the working face, whereas a gradual decrease in stress occurs in the strata behind the excavation surface, accompanied by an increase in vertical displacement. This is because the strata overlying the goaf are beginning to sink under their own weight, which is because the yield strength of the strata is gradually being exceeded [23-25]. The overburden will ultimately collapse when its deformation reaches a critical value. As shown in Figure 6(b), the displacement of the overburden in front of the working face is relatively small when the excavation of the working face has advanced up to $48 \mathrm{~m}$, whereas the displacement of the strata overlying the goaf in the back has increased. At the $40 \mathrm{~m}$ point, the displacement of the overburden reaches its maximum at $6 \mathrm{~m}$ and the corresponding stress is almost $31 \mathrm{MPa}$. This indicates that the overburden will completely collapse at this point of the roof; that is, the first weighting of the main roof occurs with a weighting interval of $40 \mathrm{~m}$. The stress data also show that large stresses occur at the $50 \mathrm{~m}$ and $60 \mathrm{~m}$ points. Therefore, periodic collapses will occur in the overlying strata of the roof as the working face continues to be excavated, with a periodic weighting interval of $10 \mathrm{~m}$. 
TABLE 1: Material parameters of the numerical model.

\begin{tabular}{|c|c|c|c|c|c|c|}
\hline Group & $\begin{array}{l}\text { Density, } \rho \\
\left(\mathrm{kg} / \mathrm{m}^{3}\right)\end{array}$ & $\begin{array}{l}\text { Elastic modulus, } \\
E\left(10^{9} \mathrm{~Pa}\right)\end{array}$ & $\begin{array}{l}\text { Poisson's } \\
\text { ratio, } v\end{array}$ & $\begin{array}{l}\text { Unconfined compressive } \\
\text { strength }(\mathrm{MPa})\end{array}$ & $\begin{array}{l}\text { Cohesion, } \\
\mathrm{C}(\mathrm{MPa})\end{array}$ & $\begin{array}{c}\text { Internal friction } \\
\text { angle, } \varphi\left({ }^{\circ}\right)\end{array}$ \\
\hline Group 1 & 2300 & 80 & 0.25 & 135 & 5.56 & 35.1 \\
\hline Group 2 & 2700 & 70 & 0.20 & 121 & 3.65 & 31.7 \\
\hline Group 3 & 1700 & 9 & 0.28 & 30 & 4.75 & 32.4 \\
\hline Group 4 & 2500 & 40 & 0.22 & 125 & 2.58 & 29.6 \\
\hline Group 5 & 1650 & 8 & 0.26 & 25 & 4.25 & 32.0 \\
\hline Group 6 & 1655 & 7 & 0.27 & 36 & 4.35 & 33.0 \\
\hline Group 7 & 1690 & 9 & 0.26 & 38 & 4.40 & 32.1 \\
\hline Group 8 & 1585 & 8 & 0.25 & 25 & 4.40 & 33.0 \\
\hline Group 9 & 1620 & 7 & 0.28 & 37 & 4.25 & 32.5 \\
\hline Group 10 & 1685 & 9 & 0.27 & 29 & 4.35 & 32.6 \\
\hline Group 11 & 1625 & 8 & 0.28 & 28 & 4.30 & 32.8 \\
\hline Group 12 & 1610 & 7 & 0.26 & 32 & 4.55 & 32.5 \\
\hline Group 13 & 1685 & 9 & 0.25 & 30 & 4.65 & 32.6 \\
\hline Group 14 & 1600 & 9 & 0.26 & 31 & 4.50 & 32.8 \\
\hline Group 15 & 1610 & 8 & 0.27 & 28 & 4.60 & 32.4 \\
\hline Group 16 & 1615 & 8 & 0.27 & 27 & 4.50 & 32.5 \\
\hline Group 17 & 1620 & 7 & 0.26 & 30 & 4.60 & 32.7 \\
\hline
\end{tabular}

\subsection{Fracture Characteristics and Deformation Law of Over-} lying Strata during the Working Face Mining. The processes of failure and deformation in the overlying strata during working face mining are shown in Figures 7 and 8 . The calculations indicate that local failures occur in the overburden of the coal seam when the working face excavation has progressed up to $4 \mathrm{~m}$; when the working face reaches $8 \mathrm{~m}$, the soft and weak strata of the false roof will collapse as excavation occurs. The immediate roof collapses when the excavation of the working face has advanced up to $20 \mathrm{~m}$. When the excavation of the working face advances up to $48 \mathrm{~m}$, the roof will fracture at the $40 \mathrm{~m}$ point; thus, forming the first weighting event. Therefore, the first weighting interval is approximately $40 \mathrm{~m}$. The rock mass near the working face will collapse after the occurrence of bending deformations, and the caved-in rock masses will fill the goaf. The overlying strata that are far from the tunnel face will collapse on a large scale after losing their bearing capacity $[26,27]$. When the excavation of the working face has reached $100 \mathrm{~m}$, the rock masses that are far from the working face will collapse continuously. The area of collapse will expand upward, leading to an appearance of fractures and bed separations in the overburden. Further, the rock masses of the separated strata sink under their own weight. This is followed by the appearance of three distinct zones in the overburden of the goaf: the collapse zone, fracture zone, and gradual settlement zone. If the excavation of the working face progresses up to $180 \mathrm{~m}$, the bed-separating cracks will develop upward and the nonuniform settlement of the overburden leads to the generation of secondary fractures. The locally developed secondary fractures will then propagate to the surface, and the area of collapse in the overburden will extend in both directions of the working face. A severe degree of surface settlement ultimately results from these processes.

4.4. The Progressive Fracture Characteristics and Deformation Law of the Overlying Strata under the Working Face Mining. A similitude model was constructed according to the methods discussed in [28-30] for studying the progressive failure and deformation of the overlying strata during the mining of the working face. Based on the similarity principles, the geometric, time, and stress similarity ratios were defined as $1 / 250,1 / 2$, and $450 / 1$, respectively. The mechanical parameters of the prototype are listed in Table 1. The similarity materials and their mixing ratios were determined according to $[31,32]$. The progressive fracture and deformation of the overlying strata in a variety of mining conditions are shown in Figure 9. Referring to the numerical simulation results, the model test results are analyzed, and the similarities are given. In Figure 9(a), it is shown that the overburden remained largely intact when the excavation of the working face advanced up to $4 \mathrm{~m}$, without showing any significant signs of damage. Figure 9(b) shows that the softer and weaker sections of the roof began to cave-in when the excavation of the working face reached $8 \mathrm{~m}$; collapses also occurred in local sections of the overburden. In Figure 9(c), it is shown that the immediate roof collapsed when the excavation of the working face reached $20 \mathrm{~m}$. The area of collapse in the overlying strata was expanded and the localized fractures that were formed previously began to propagate to the rest of the overburden. The bed-separating cracks have also formed in the overburden, which indicates that the stability of the overburden has begun to deteriorate. The settlement of the overburden also becomes quite apparent in this stage. Figure 9(d) shows that the entirety of the overburden begins to collapse when the excavation of the working face reaches $40 \mathrm{~m}$, which indicates that the overlying strata exhibits "pseudoplastic beam"-like mechanical characteristics upon the relief of local stresses in the overlying strata. This manifests as a downward sag at the center of the overburden and large displacements at the center. Fractures also occurred at stress concentrations on both ends of the working face, which led to the formation of a "trapezoidal" fracture. In addition, the bed-separating cracks continued to develop until they reached the surface of the 


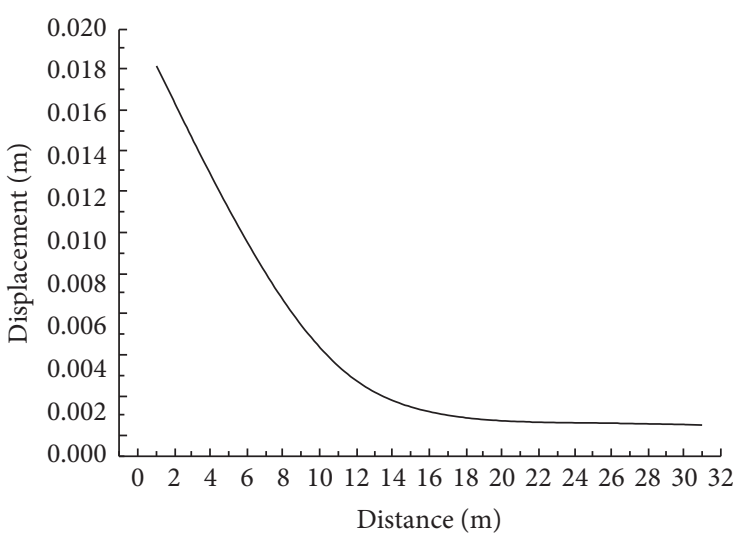

_ Face to $4 \mathrm{~m}$

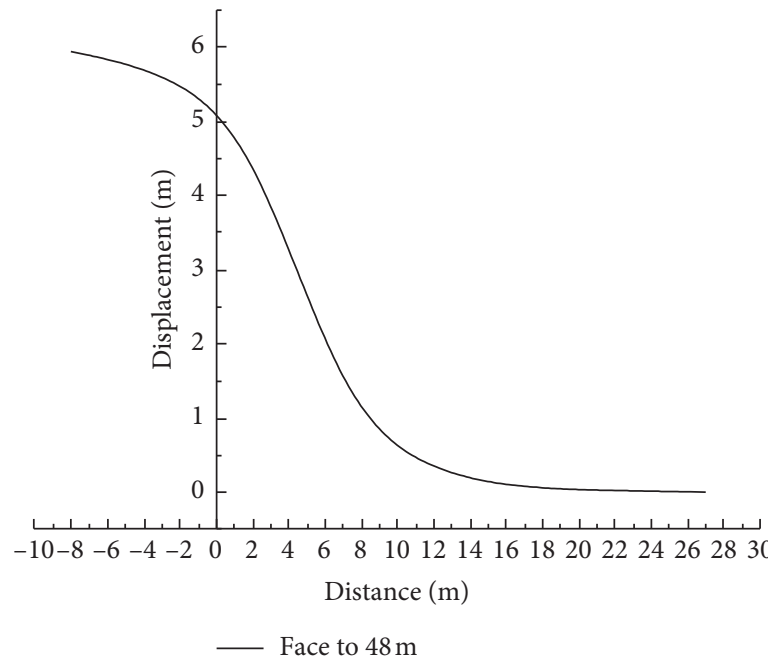

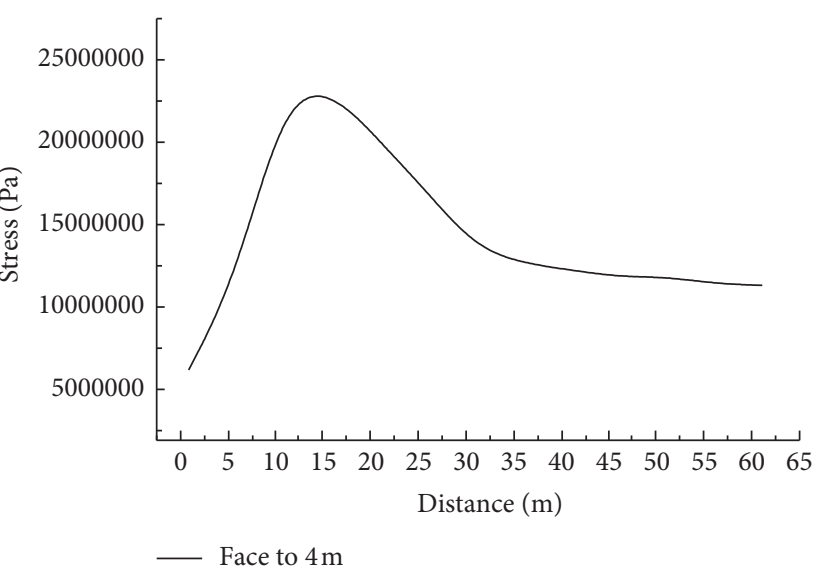

(a)

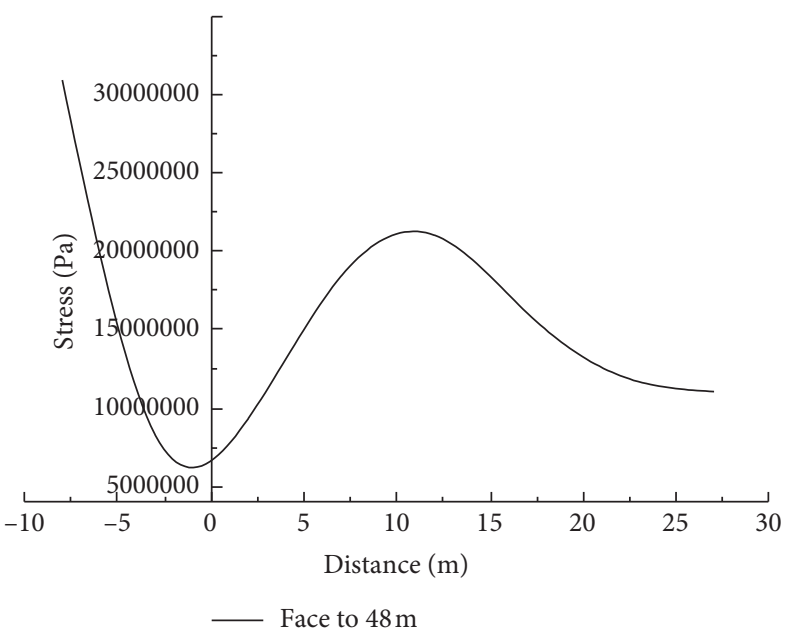

(b)

Figure 6: Calculated advanced abutment stresses and overlying strata displacements. (a) Initial stage. (b) Weighting stage.

overburden; thus, these cracks display a tendency to propagate upward along the overburden. Figure 9(e) indicates that in the absence of abutments, the entirety of the overburden will collapse when the excavation of the working face reaches $100 \mathrm{~m}$. In this figure, it is shown that the area of collapse has expanded upward and formed a distinct "three-zone" distribution. During the formation of this "three-zone" distribution, the constraints imposed by the compression of the strata and the "trapezoidal" fracture formed around the fractures cause the boundaries of the "three-zone" distribution to take a trapezoidal form. Thus, a trapezoidal compacted zone was formed in the deformed strata. In addition, the continued development of bedseparating cracks leads to the formation of $35-40 \mathrm{~m}$ wide fractured zones on both sides of the compacted zone. The continued excavation of the working face up to $180 \mathrm{~m}$, under these conditions, led to the propagation of the collapsed zone to the ground surface, as shown in Figure 9(f). As the excavation continued, stress was transferred toward both sides of the overburden, which accelerated the development of fractures in the fractured zones. Some of the fractures in the fractured zone developed up to the ground surface. Furthermore, the nonuniform settlement of the overburden induced the generation of secondary fractures in the adjacent regions. Due to the disturbances caused by the secondary fractures and the subsidence of the overlying strata, one may surmise that severe ground surface settlement will occur after rock burst failures in the overburden [33, 34]. Based on [35-37], further excavation of the working face is no longer possible, and the excavation must be stopped to allow for an appropriate level of reinforcement. The results of this similitude experiment are consistent with those of the numerical calculations, thereby indicating that the results of both the experiments are valid. This also indicates that the results of the theoretical derivations are applicable for practical applications. Thus, the findings of this work will provide a useful source of scientific guidance for practical engineering works in the future. 


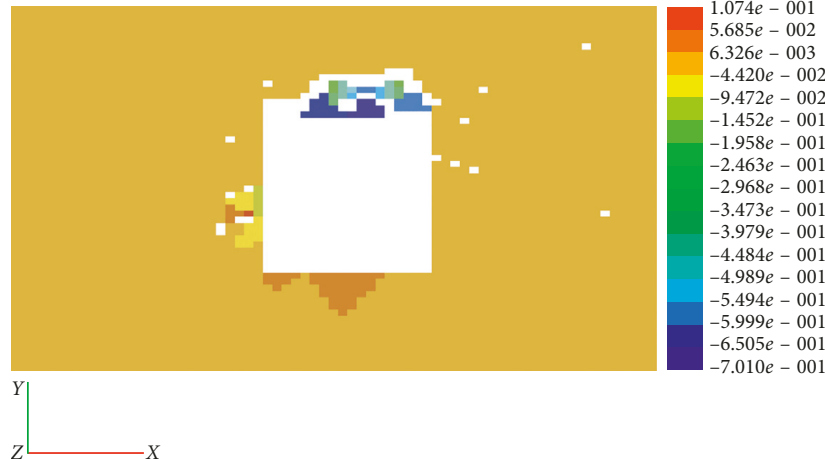

(a)
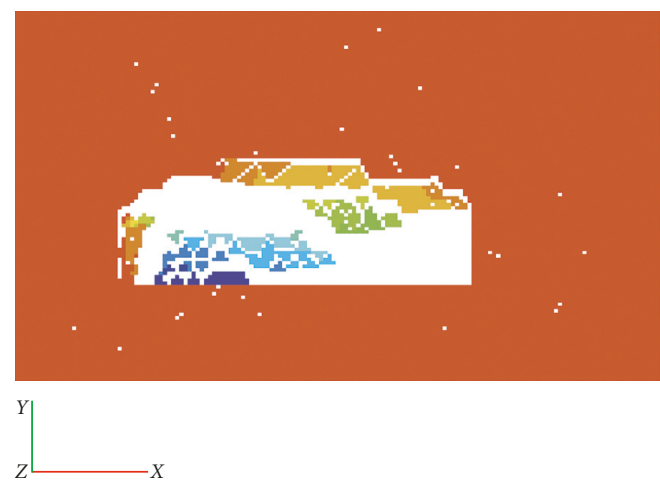

(c)

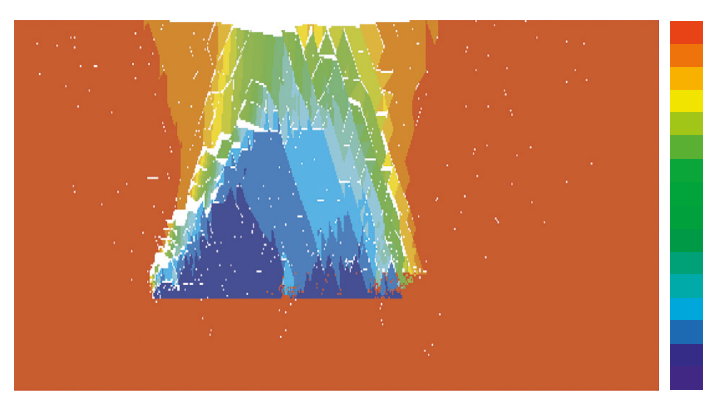
${ }_{Z}^{Y}{ }^{Y}$

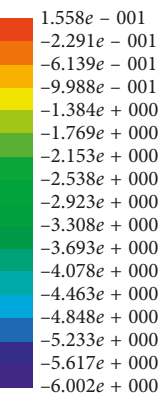

$-6.002 e+000$

$$
\text { Y }
$$

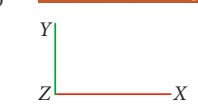$$
\text { : }
$$

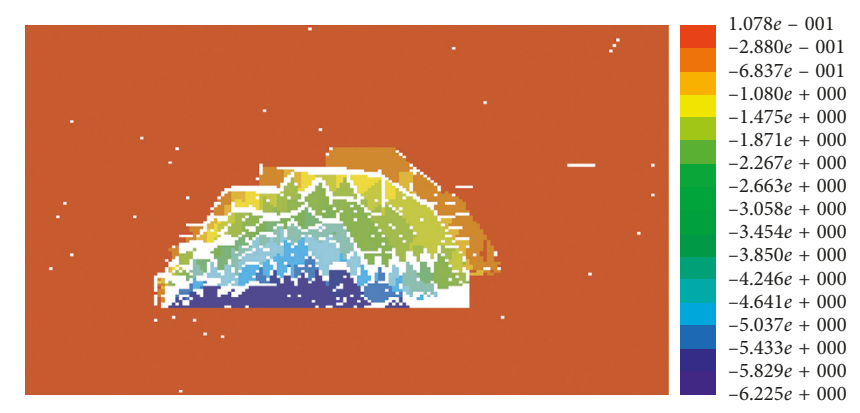

(d)

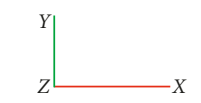

(e)

(f)

Figure 7: The fracture characteristics and horizontal displacement variation of overlying strata during the working face mining. (a) Mining to $4 \mathrm{~m}$, (b) mining to $8 \mathrm{~m}$, (c) mining to $20 \mathrm{~m}$, (d) mining to $40 \mathrm{~m}$, (e) mining to $100 \mathrm{~m}$, and (f) mining to $180 \mathrm{~m}$.

\section{Conclusions}

In this study, the destabilization mechanisms and the patterns of overburden deformation and failure during underground resource mining were investigated via theoretical analyses, numerical simulations, and model experiments, based on the excavation of the 13210 working face in the Yima coal mine of the Gengcun village. The following conclusions were drawn from this study:

(1) The degradation of overburden mechanical properties due to mining-induced disturbances is an important factor for the occurrence of rock burst failures in the overlying strata. If the geometric parameters of the working face are fully determined, a stiffness ratio no greater than 1 is required for the occurrence of rock burst failures in the overburden.

(2) During the excavation of a working face, the stress values of the advanced abutments decrease with a decrease in distance from the tunnel face. As the distance from the tunnel face increases, the stresses acting upon the tunnel face's advanced abutments initially increase before decreasing and stabilizing at some value; this corresponds to the existence of the "stress build-up zone," "stress reduction zone," and "native rock stress zone" in the overburden. 

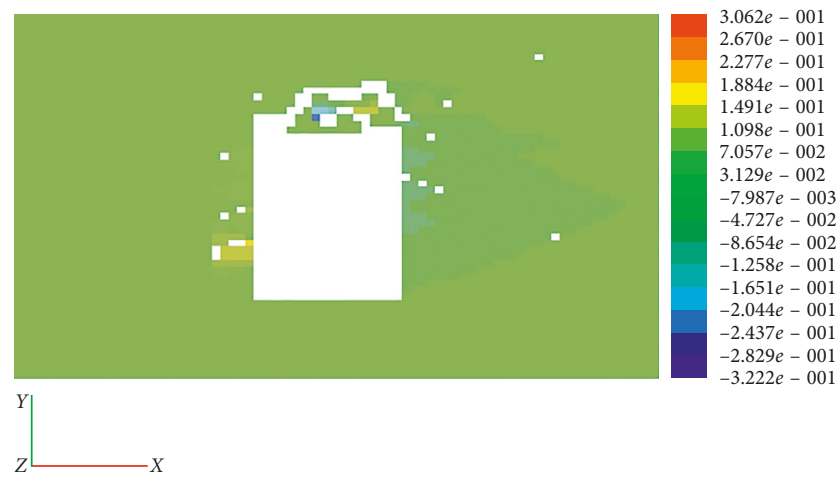

(a)
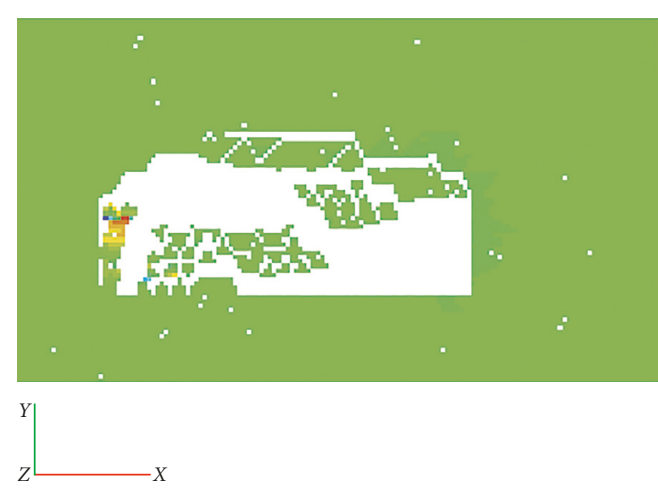

(c)
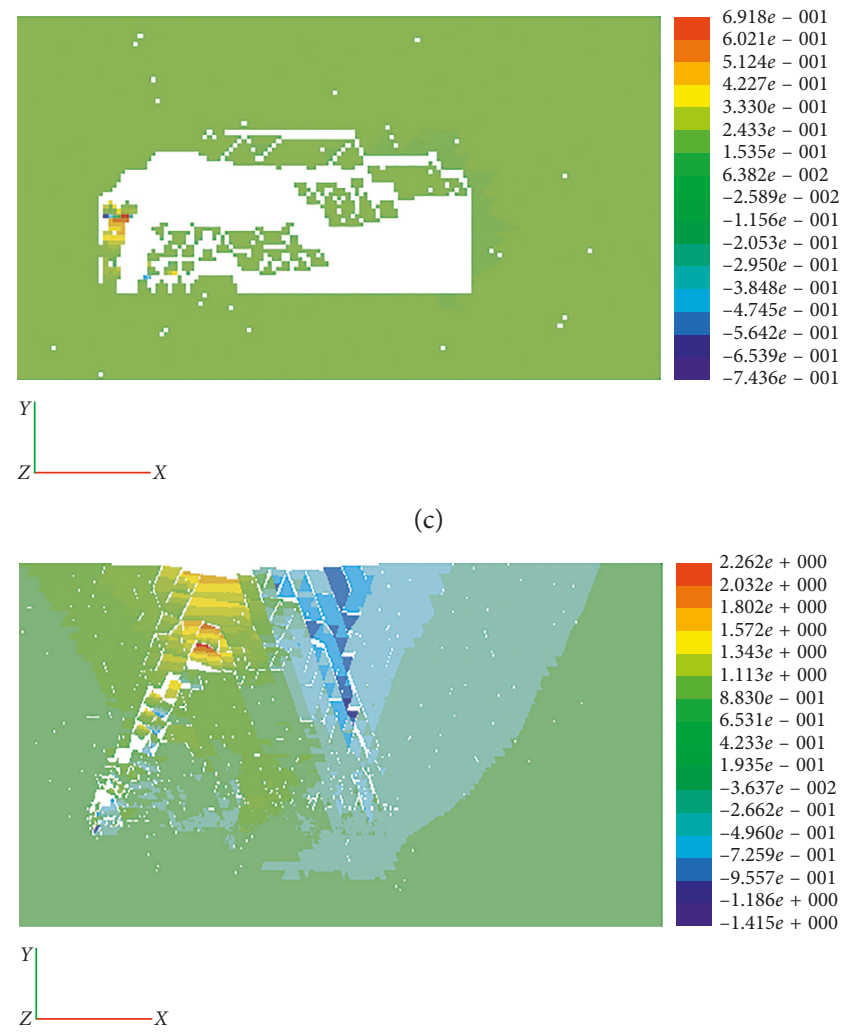

(e)

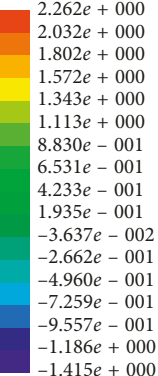

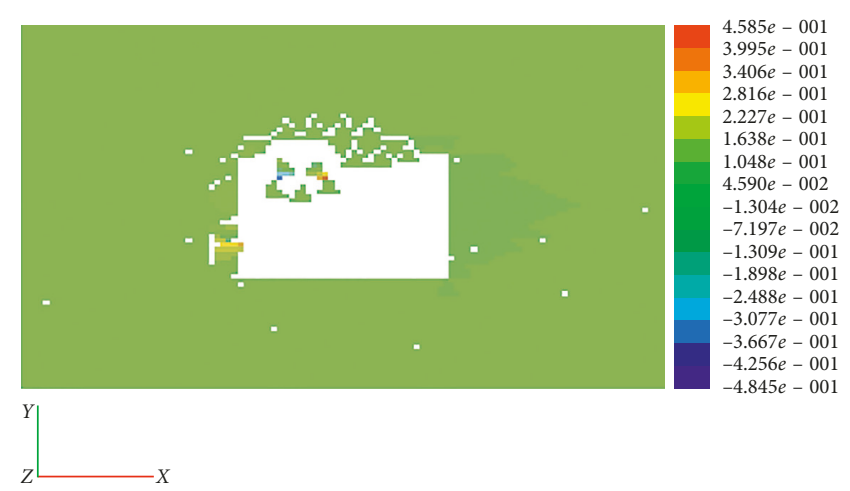

(b)
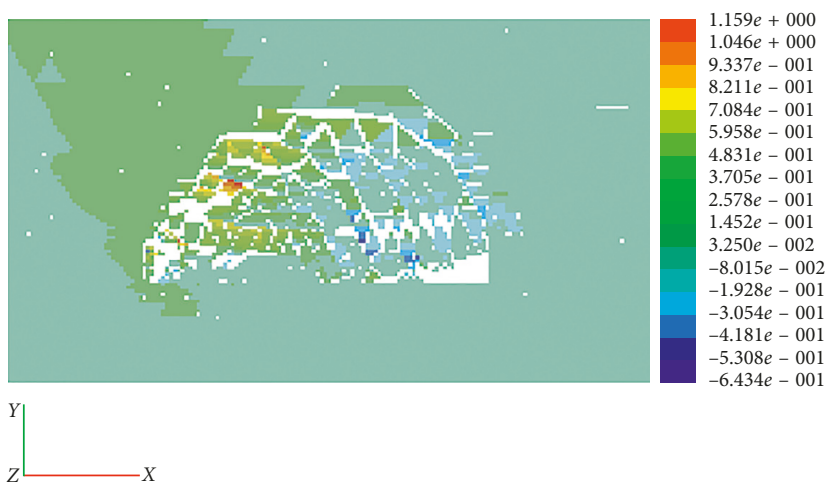

(d)

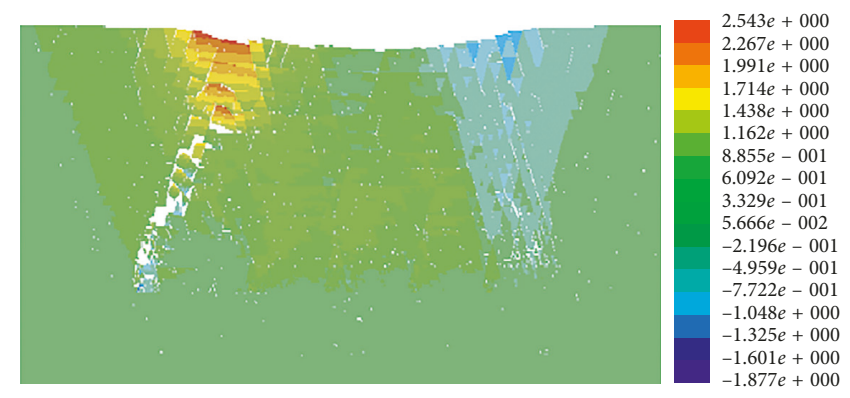

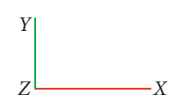

$1.415 e+$

(f)

Figure 8: The fracture characteristics and vertical displacement variation of overlying strata during the working face mining. (a) Mining to $4 \mathrm{~m}$, (b) mining to $8 \mathrm{~m}$, (c) mining to $20 \mathrm{~m}$, (d) mining to $40 \mathrm{~m}$, (e) mining to $100 \mathrm{~m}$, and (f) mining to $180 \mathrm{~m}$.

(3) During the mining processes, the overburden exhibits a "pseudoplastic beam" stress state upon the complete release of local stresses in the overburden. Further, a "trapezoidal" fracture is formed by the cracks at stress concentrations. The continued progression of excavation expands the area of collapse in the overlying strata and increases the areas of fracture and compacted zones. More stress will then be transferred toward both ends of the working face to form high-stress zones in these areas, which ultimately leads to the formation of a "three-zone" distribution.
(4) The progression of the working face excavation is accompanied by upward expansions in the overburden's area of collapse and propagation of upward-growing bed-separating cracks; these are the key factors for the occurrence of ground settlement. Further, the nonuniform settlement of the overburden induces the generation of secondary fractures, which in turn expands the area of collapse of the overburden toward either end of the working face; this is an important factor that causes the exacerbation of surface settlement. 


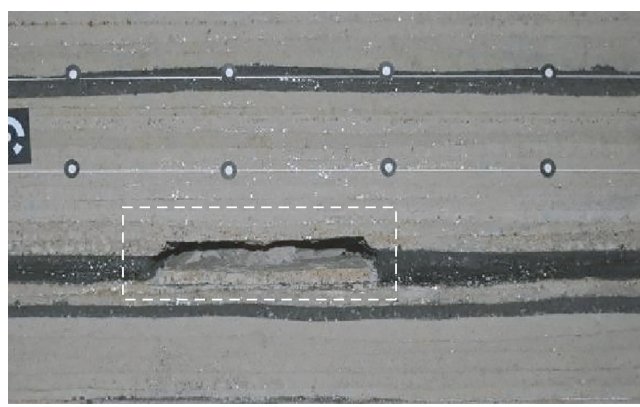

(a)

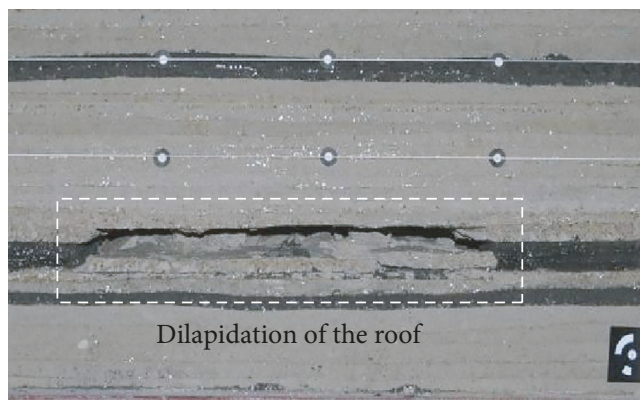

(c)

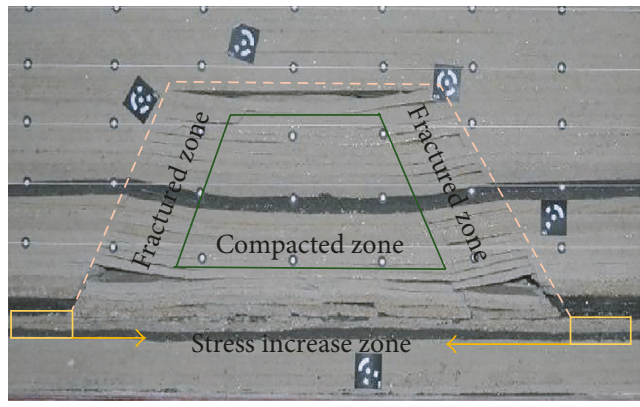

(e)

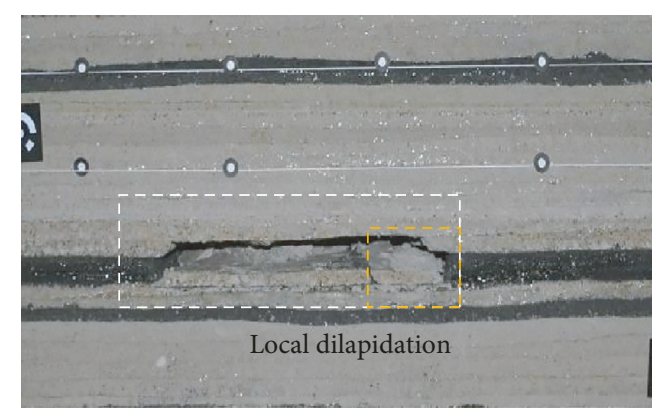

(b)

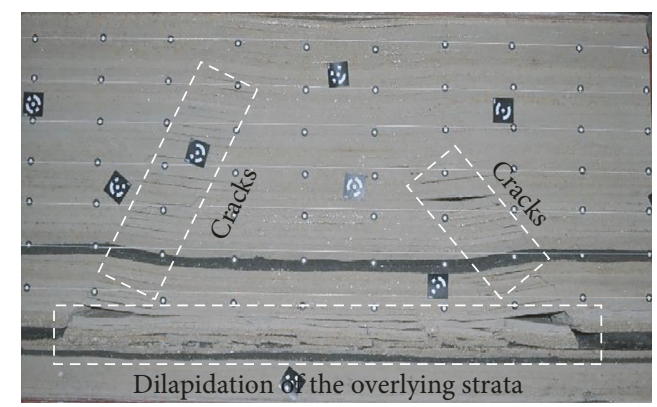

(d)

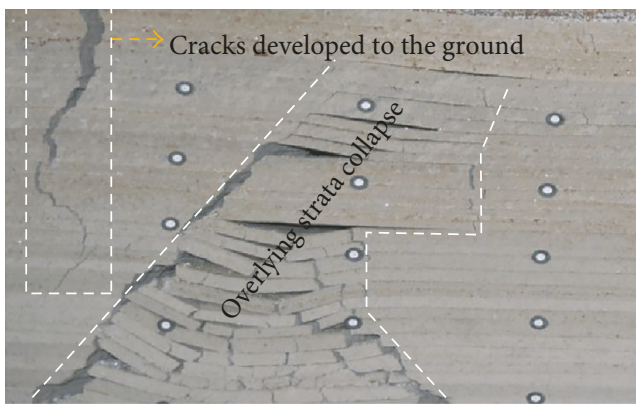

(f)

Figure 9: Progressive fracture and deformation of the overlying strata during the mining of the working face. (a) Mining up to $4 \mathrm{~m}$, (b) mining up to $8 \mathrm{~m}$, (c) mining up to $20 \mathrm{~m}$, (d) mining up to $40 \mathrm{~m}$, (e) mining up to $100 \mathrm{~m}$, and (f) mining up to $180 \mathrm{~m}$.

(5) The results of our theoretical analyses, numerical calculations, and model experiments were completely consistent with each other. Thus, the findings of this work will be a useful source of scientific guidance for practical engineering works in the future.

\section{Data Availability}

The data used to support the findings of this study are available from the corresponding author upon request.

\section{Conflicts of Interest}

The authors declare that they have no conflicts of interest.

\section{Acknowledgments}

This work was supported by the Special Funds for Central Guiding Local Science and Technology Development (Project no. Z161100004516014), National Natural Science Foundation of China (Project nos. 51504029 and 51774048), and Beijing Nova Program (Project no. Z161100004916083).

\section{References}

[1] J. Tang, J. A. Wang, and L. Wang, "Dynamic laws and characteristics of surface movement induced by mining under thin alluvium," Rock and Soil Mechanics, vol. 35, no. 10, pp. 2958-2968, 2014.

[2] M. G. Qian, P. W. Shi, and J. L. Xv, Mining Pressure and Strata Control, China University of Mining and Technology Press, Xuzhou, China, 2010. 
[3] M. G. Qian, X. X. Miao, and J. L. Xu, "Theoretical study of key stratum in ground control," Journal of China Coal Society, vol. 21, no. 3, pp. 225-230, 1996.

[4] X. X. Miao, R. H. Chen, and H. Pu, "Analysis of breakage and collapse of thick key strata around coal face," Chinese Journal of Rock Mechanics and Engineering, vol. 24, no. 8, pp. 1289$1295,2005$.

[5] L. X. Wu, J. Z. Wang, and Y. A. Liu, Coal Strip Mining under Buildings: Theory and Practice, China University of Mining and Technology Press, Xuzhou, China, 1994.

[6] P. A. Cundall, "A computer model for simulating progressive large-scale movements in blocky rock systems," in Proceedings of the ISRM Symposium on Rock Fracture, pp. 11-18, Nancy, France, 1971.

[7] K. M. O'Connor and C. H. Dowding, "Distinct element modeling and analysis of mining induced subsidence," Rock Mechanics and Rock Engineering, vol. 25, no. 1, pp. 1-24, 1992.

[8] S. H. Li, M. H. Zhao, Y. N. Wang, and Y. Rao, "A new computational model of three-dimensional DEM-block and particle model," International Journal of Rock Mechanics and Mining Sciences, vol. 41, no. 3, p. 436, 2004.

[9] F. Li, J. A. Wang, P. F. Li, and K. Huang, "Research on movement behavior and failure mechanism of overlying strata caused by mining at mountainous field," Rock and Soil Mechanics, vol. 37, no. 4, pp. 1089-1095, 2016.

[10] L. M. Dou, J. He, and A. Cao, "Rock burst prevention methods based on theory of dynamic and static combined load induced in coal mine," Journal of China Coal Society, vol. 40, no. 7 , pp. 1469-1476, 2015.

[11] X. B. Li, S. M. Wang, L. Weng, L. Q. Huang, T. Zhou, and J. Zhou, "Damage constitutive model of different age concretes under impact load," Journal of Central South University, vol. 22, no. 2, pp. 693-700, 2015.

[12] Z. Q. Yin, X. B. Li, J. F. Jin, X. Q. He, and K. Du, "Failure characteristics of high stress rock induced by impact disturbance under confining pressure unloading," Transactions of Nonferrous Metals Society of China, vol. 22, no. 1, pp. 175-184, 2012.

[13] M. F. Cai, J. A. Wang, and S. H. Wang, "Analysis on energy distribution and prediction of rock burst during deep mining excavation in Linglong gold mine," Chinese Journal of Rock Mechanics and Engineering, vol. 20, no. 1, pp. 38-42, 2001.

[14] S. C. Li, W. S. Zhu, and W. Z. Chen, "Application of elastoplastic large displacement finite element method to the study of deformation prediction of soft rock tunnel," Chinese Journal of Rock Mechanics and Engineering, vol. 21, no. 4, pp. 466-470, 2002.

[15] H. W. Song, Y. X. Jia, and Y. Y. Duan, "Study on characteristics of rock broken by excavation and roof supporting object," Journal of China University of Mining and Technology, vol. 35, no. 2, pp. 192-196, 2006.

[16] F. Q. Gong and G. F. Zhao, "Dynamic indirect tensile strength of sandstone under different loading rates," Rock Mechanics and Rock Engineering, vol. 47, no. 6, pp. 2271-2278, 2014.

[17] Y. P. Wu, Y. G. Yang, and P. S. Xie, "Application of cusp catastrophe theory to research of mine water inrush law from roof," Coal Science and Technology, vol. 35, no. 3, pp. 37-40, 2007.

[18] C. Feng and S. H. Li, "2D particle contact-based meshfree method in CDEM and its application in geotechnical problems," Engineering Computations, vol. 32, no. 4, pp. 10801103, 2015.

[19] Z. S. Ma, C. Feng, T. P. Liu, and S. H. Li, “A GPU accelerated continuous-based discrete element method for elastodynamics analysis," Advanced Materials Research, vol. 320, pp. 329-34, 2011.

[20] H. C. Hu, Variational Principle of Elasticity and Its Application, Science Press, Beijing, China, 1981.

[21] W. C. Qian, "Variational principles in elasticity with nonliner stress-strain relation," Applied Mathematics and Mechanics, vol. 8, no. 7, pp. 567-577, 1987.

[22] F. Qiu and H. Ding, "Finite element method simulating failure of rock material," Chinese Journal of Rock Mechanics and Engineering, vol. 26, no. S1, pp. 2663-2668, 2006.

[23] R. Q. Huang, "Geo-stress distribution and unloading fracturing mechanism of high rock slopes in western part of China," Journal of Engineering Geology, vol. 12, pp. 7-13, 2004.

[24] F. Q. Wu, T. Liu, X. L. Tang et al., "Research on unloading and zonation of rock mass dam foundation excavation-a case study of Xiaowan hydropower station," Chinese Journal of Rock Mechanics and Engineering, vol. 28, no. 6, pp. 1091-1098, 2009.

[25] D. Huang, Q. Tan, and R. Q. Huang, "Study of micromesoscopic characteristics of marble fracture surface and correlation with unloading rock mass strength under high stress and unloading," Rock and Soil Mechanics, vol. 33, no. S2, pp. 7-15, 2012.

[26] X. P. Zhou, Q. H. Qian, and B. H. Zhang, "Zonal disintegration mechanism of deep crack-weakened rock masses under dynamic unloading," Acta Mechanica Solida Sinica, vol. 22, no. 3, pp. 240-250, 2009.

[27] H. Q. Xie and C. H. He, "Study of the unloading characteristics of a rock mass using the triaxial test and damage mechanics," International Journal of Rock Mechanics and Mining Sciences, vol. 41, no. S1, pp. 74-80, 2004.

[28] P. L. Gong, Y. Q. Hu, Y. S. Zhao, and D. Yang, "Threedimensional simulation study on law of deformation and breakage of coal floor on mining above aquifer," Chinese Journal of Rock Mechanics and Engineering, vol. 24, no. 23, pp. 4396-4402, 2005.

[29] J. W. Wu, H. S. Tong, S. J. Tong, and D. Q. Tang, "Study on similar material for simulation of mining effect of rock mass at fault zone," Chinese Journal of Rock Mechanics and Engineering, vol. 26, no. S2, pp. 4170-4175, 2007.

[30] W. D. Song, J. X. Fu, and D. X. Wang, "Study on physical and numerical simulation of failure laws of wall rock due to transformation from open-pit to underground mining," Journal of China Coal Society, vol. 37, no. 2, pp. 186-191, 2012.

[31] W. M. Cheng, L. L. Sun, G. Wang, and X. C. Huang, "Similar material simulation test of steep-inclined extra-thick coal seam," Journal of Mining and Safety Engineering, vol. 33, no. 3, pp. 387-392, 2016.

[32] J. Xiao, "Selection of similar materials for model test and research on similar material proportioning test," M.S. thesis, Beijing Jiaotong University, Beijing, China, 2013.

[33] B. Orlecka-Sikora, S. Lasocki, G. Lizurek, and L. Rudziński, "Response of seismic activity in mines to the stress changes due to mining induced strong seismic events," International Journal of Rock Mechanics and Mining Sciences, vol. 53, pp. 151-158, 2012.

[34] A. Sainoki and H. S. Mitri, "Dynamic behavior of mininginduced fault slip," International Journal of Rock Mechanics and Mining Sciences, vol. 66, pp. 19-29, 2014.

[35] D. P. Ma, T. X. Wang, and Y. Liu, "An analysis of "space-time" relationship of gob-side entry driving in dynamic pressure area," Journal of Mining and Safety Engineering, vol. 32, no. 3, pp. 465-470, 2015. 
[36] CUMT, "Study on stress transmission laws of mining floor and its influence on stability of floor roadway," M.S. thesis, China University of Mining and Technology, Xuzhou, China, 2011.

[37] H. Wang, Y. Jiang, S. Xue et al., "Influence of fault slip on mining-induced pressure and optimization of roadway support design in fault-influenced zone," Journal of Rock Mechanics and Geotechnical Engineering, vol. 8, no. 5, pp. 660-671, 2016. 


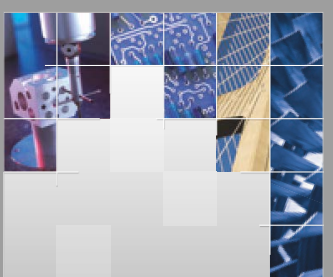

\section{Enfincering}
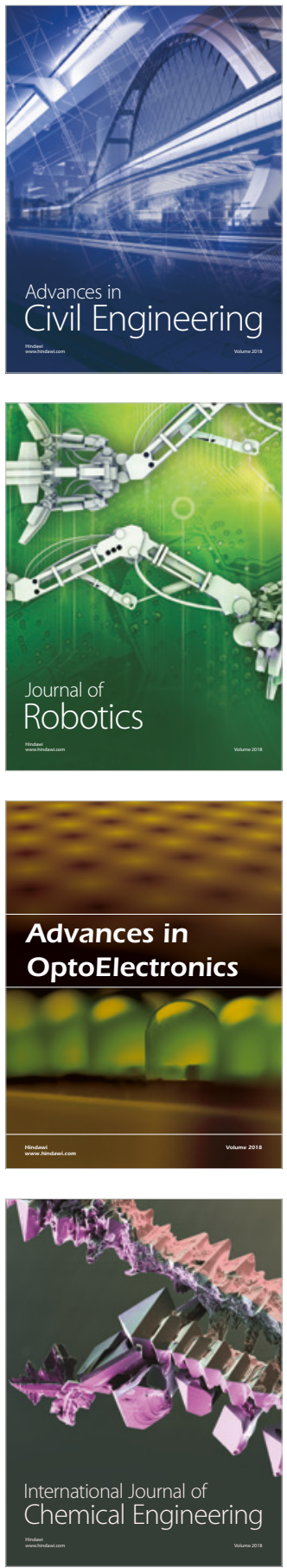

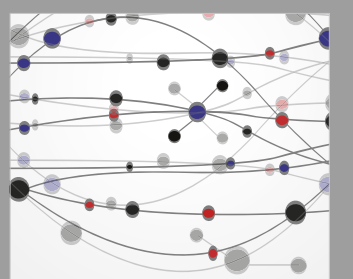

\section{Rotating \\ Machinery}

The Scientific World Journal

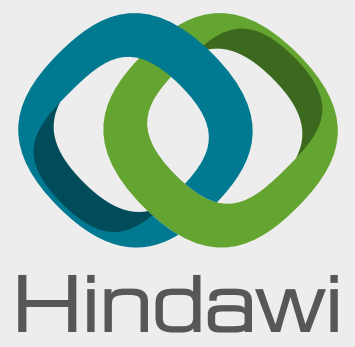

Submit your manuscripts at

www.hindawi.com
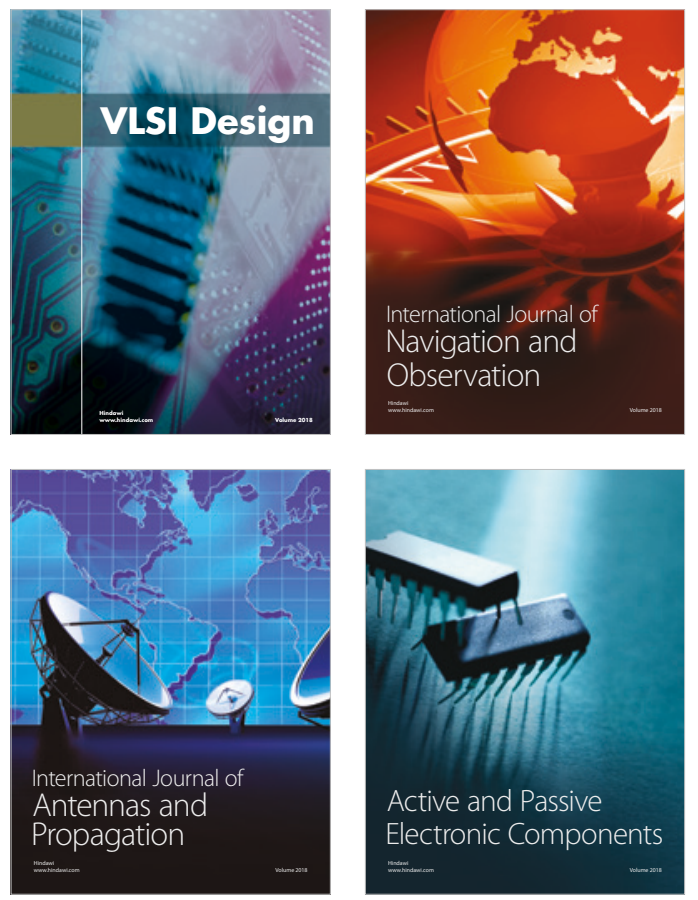
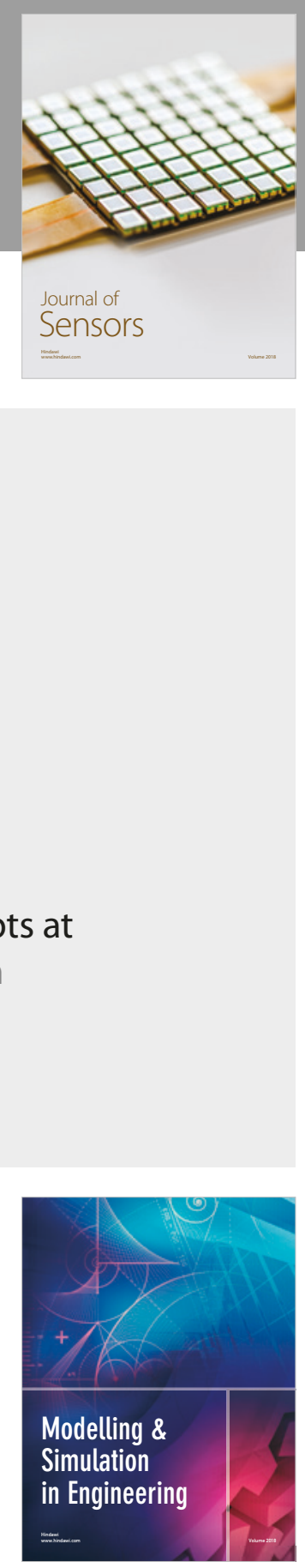

\section{Advances \\ Multimedia}
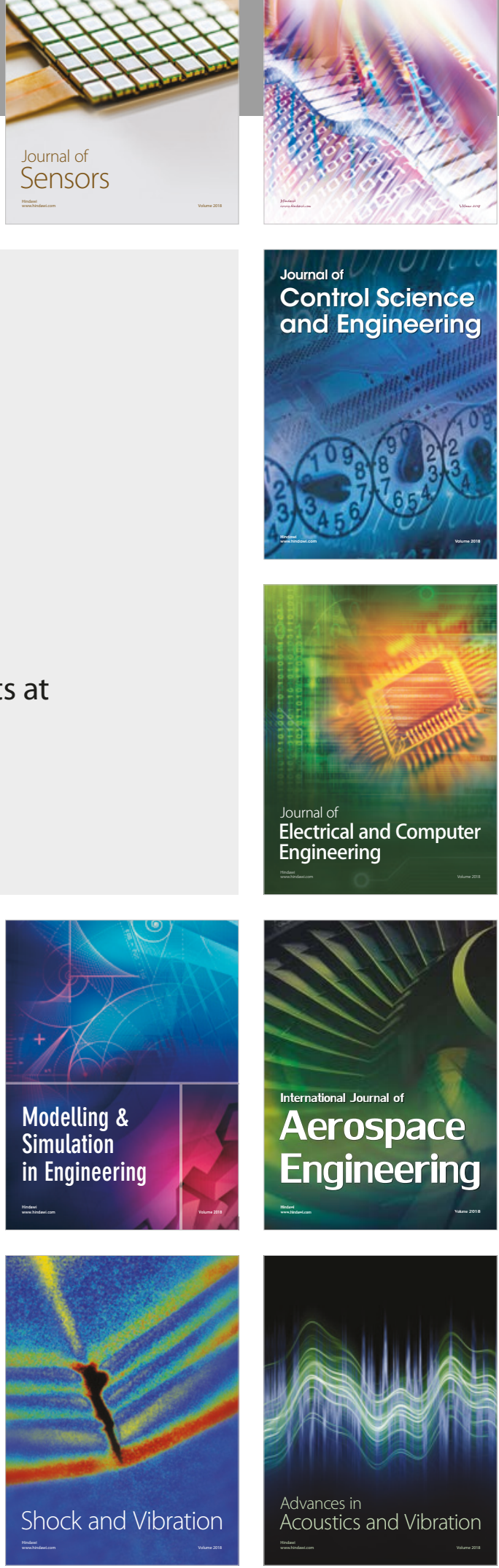